\title{
UNIVERSITYOF
}

FORWARD

THINKING

WESTMINSTER用

WestminsterResearch

http://www.westminster.ac.uk/westminsterresearch

\section{On the "blindness" of blindsight: What is the evidence for phenomenal awareness in the absence of primary visual cortex} (V1)?

Mazzi, C., Savazzi, S. and Silvanto, J.

NOTICE: this is the authors' version of a work that was accepted for publication in Neuropsychologia. Changes resulting from the publishing process, such as peer review, editing, corrections, structural formatting, and other quality control mechanisms may not be reflected in this document. Changes may have been made to this work since it was submitted for publication. A definitive version was subsequently published in Neuropsychologia, DOI: 10.1016/j.neuropsychologia.2017.10.029, 2017.

The final definitive version in Neuropsychologia is available online at:

https://dx.doi.org/10.1016/j.neuropsychologia.2017.10.029

(C) 2017. This manuscript version is made available under the CC-BY-NC-ND 4.0 license http://creativecommons.org/licenses/by-nc-nd/4.0/

The WestminsterResearch online digital archive at the University of Westminster aims to make the research output of the University available to a wider audience. Copyright and Moral Rights remain with the authors and/or copyright owners.

Whilst further distribution of specific materials from within this archive is forbidden, you may freely distribute the URL of WestminsterResearch: ((http://westminsterresearch.wmin.ac.uk/)).

In case of abuse or copyright appearing without permission e-mail repository@westminster.ac.uk 


\section{Author's Accepted Manuscript}

On the "blindness" of blindsight: What is the evidence for phenomenal awareness in the absence of primary visual cortex (V1)?

Chiara Mazzi, Silvia Savazzi, Juha Silvanto

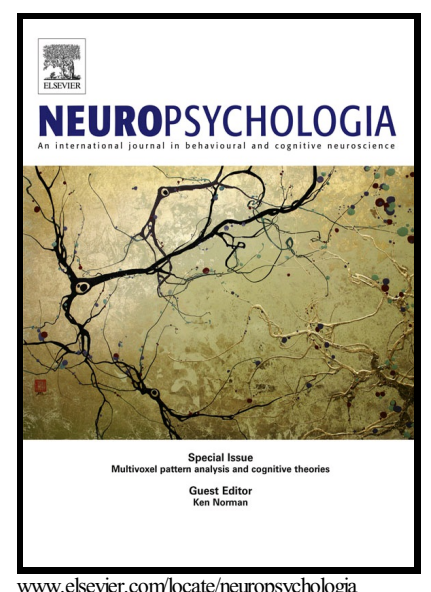

PII: $\quad$ S0028-3932(17)30405-0

DOI: $\quad$ https://doi.org/10.1016/j.neuropsychologia.2017.10.029

Reference: NSY6548

To appear in: Neuropsychologia

Received date: 20 June 2017

Revised date: 17 October 2017

Accepted date: 23 October 2017

Cite this article as: Chiara Mazzi, Silvia Savazzi and Juha Silvanto, On the "blindness" of blindsight: What is the evidence for phenomenal awareness in the absence of primary visual cortex (V1)?, Neuropsychologia, https://doi.org/10.1016/j.neuropsychologia.2017.10.029

This is a PDF file of an unedited manuscript that has been accepted for publication. As a service to our customers we are providing this early version of the manuscript. The manuscript will undergo copyediting, typesetting, and review of the resulting galley proof before it is published in its final citable form. Please note that during the production process errors may be discovered which could affect the content, and all legal disclaimers that apply to the journal pertain. 
On the "blindness" of blindsight: what is the evidence for phenomenal awareness in the absence of primary visual cortex (V1)?

Chiara Mazzi $^{1,2}$, Silvia Savazzi ${ }^{1,2}$ and Juha Silvanto ${ }^{3}$

${ }^{1}$ University of Verona and National Institute of Neuroscience-Italy

${ }^{2}$ Perception and Awareness (PandA) Laboratory, Department of Neurological, Biomedical and Movement Sciences, University of Verona, Italy

${ }^{3}$ Department of Psychology, Faculty of Science and Technology, University of Westminster, WIB 2HW London, United Kingdom,

\section{Correspondence to:}

chiara.mazzi@univr.it

silvia.savazzi@univr.it

j.silvanto@westminster.ac.uk 


\begin{abstract}
Blindsight has been central to theories of phenomenal awareness; that a lesion to primary visual cortex (V1) abolishes all phenomenal awareness while unconscious visual functions can remain has led to the views that this region plays in generating visual consciousness. However, since the early $20^{\text {th }}$ century, there have been reports, many of which controversial, of phenomenal awareness in patients with V1 lesions. These reports include selective sparing of motion awareness, hemianopic completion and visual aftereffects. More recently, there have been successful attempts of inducing visual qualia with noninvasive brain stimulation. Here we critically review this evidence and discuss their implications to theoretical understanding of phenomenal awareness.
\end{abstract}

Keywords: primary visual cortex (V1), phenomenal awareness, blindsight, hemianopic completion, afterimages, Transcranial Magnetic Stimulation 


\section{Introduction}

Damage or disconnection of all or some parts of the primary visual cortex (V1) results in a region of blindness (a scotoma) in the corresponding portion of the visual field (Holmes, 1945). Nevertheless, some patients with such lesions are able to detect, localize and discriminate stimuli presented in their impaired visual field in the absence of phenomenal awareness (Pöppel et al., 1973; Weiskrantz et al., 1974). For this phenomenon, the term "blindsight" was coined (Weiskrantz et al., 1974) to highlight the dissociation between the absence of conscious perception of items which can be detected at above-chance level. Blindsight has been influential in guiding neural models of phenomenal awareness: the finding that the surviving cortex is unable to generate qualia despite continuing to process visual information appears to suggest unique role for $\mathrm{V} 1$ in conscious experience (see e.g. Cowey, 2010, 2004 for informative reviews).

However, there have been numerous reports of patients with V1 lesions not being fully unaware of events in the blind field. One form of awareness has been described as a "feeling" of something happening in the blind field with no accompanying visual qualia; this type of awareness (which has no phenomenal content) is referred to as blindsight Type 2 (Weiskrantz, 1998). Interestingly, some patients with V1 lesion also appear to experience visual qualia in their blind field (Richards, 1973). Such findings are of great theoretical interest, given the influential models linking V1 to phenomenal awareness (e.g. Lamme, 2003). Here we critically review the empirical evidence of such phenomenal awareness in the absence of V1, with a special focus on individuals with blindsight.

\section{Phenomenal awareness resulting from visually presented stimuli in the blind field}

Evidence for phenomenal awareness triggered by visual stimuli in the blind field of individuals with V1 lesions has come from three separate phenomena. Firstly, there are numerous reports of residual awareness for a particular stimulus feature (mostly motion) within the blind field. Secondly, stimuli intruding both the sighted and blind field can trigger hemianopic completion, such that the blind field component of the stimulus is also phenomenally perceived. Thirdly, stimuli presented in the blind field can trigger after-images, even when the inducing stimulus is not perceived.

\section{Riddoch's syndrome}

The most frequently cited (and arguably also most controversial) cases of phenomenal awareness in patients with V1 lesions involve the experience of visual motion qualia in the absence of awareness for other stimulus features. This residual ability was first described by George Riddoch who studied patients rendered blind by gunshot wounds damaging V1 (Riddoch, 1917). This so-called Riddoch syndrome has been extensively investigated behaviourally (ffytche and Zeki, 2011; Zeki and ffytche, 1998), by means of brain imaging (Barbur, Watson, Frackowiak, \& Zeki, 1993; Zeki \& ffytche, 1998) and electrophysiology (ffytche et al., 1996). Its key 
characteristic is that patients report phenomenally experiencing the presence of motion, especially for high speed stimuli (e.g. ffytche and Zeki, 2011; Weiskrantz et al., 1995; Zeki and ffytche, 1998), but not other stimulus attributes. Riddoch syndrome is not always associated with blindsight, as it also occurs in hemianopic patients who do not display above chance-level detection performance for blind field stimuli (e.g. Benson et al., 1998; Mazzi et al., 2016; Morland, 1999). Neuroimaging studies have showed that activity in the motion selective area $\mathrm{V} 5 / \mathrm{MT}+$ (but not in early visual areas) correlates with the reports of motion awareness visual areas (Barbur et al., 1993; ffytche et al., 1996; Zeki \& ffytche, 1998).

However, it is unclear whether Riddoch's syndrome is a real condition or reflects lack of knowledge regarding the extent of lesions and difficulties in interpreting patients' subjective responses. In Riddoch's early studies, there is no evidence of whether the V1 lesions were complete (e.g. Teuber et al., 1960); this precludes any conclusions regarding the ability to perceive qualia in the absence of V1. Indeed, a parsimonious explanation is that the lesions were incomplete and surviving parts of V1 enabled the experience of motion. A second issue relates to the nature of psychophysical assessments. Inferring a differential performance level on two stimulus types requires that the two are matched for difficulty when this is done, selective sparing of motion detection is no longer observed in blindsight patients (Azzopardi and Cowey, 2001, 1997). Methodological issues are also important, such as robust monitoring of eye movements to ensure that participants are not using their sighted field to perform the task. For example, in the study by Zeki and ffytche (2011), where phenomenal awareness was found, monitoring of eye movements was carried out by the experimenter monitored fixation by facing the subject behind the laptop and observing their eyes throughout each trial. Such a method might not be sufficiently sensitive to conclusively rule out eye movements. A third, and perhaps the most challenging issue to resolve relates to patients' subjective reports of "awareness". While there is little doubt that Riddoch's patients (in whom the extent of V1 lesion is unknown) did experience motion qualia, the picture is much less clear in individuals in whom absence of V1 has been confirmed by MRI. An example is the well-known blindsight subject GY, of whom it was claimed that he "...was able to discriminate correctly and faultlessly and to have conscious awareness of having seen the particular visual stimulus" (Barbur et al., 1993). In some reports, his visual experience is described in terms of "shadows" and "looking through closed lids" (Zeki \& ffytche, 1998). However, in an interview with Larry Weiskrantz (1997), he described his blind field experience as follows: "you don't actually ever sense anything or see anything...its more an awareness but you don't see it....it is a sense that I haven't got.... if you said something to try to describe sight to a blind man, we don't have the words to do it because he does not have the receptors or the reception, and that is the same with me. I mean I can't describe something I don't understand myself'. From this description GY appears to display Type 2 blindsight in respect to visually presented motion. 
Evidence of residual vision has also been reported with other stimulus features. For example, hemianopic patients, with or without blindsight, have been found to be aware of high contrast, low frequency, high displacement and to a lesser extent colour of stimuli presented in the blind field (Barbur et al., 1999; Bollini et al., 2017; Kentridge et al., 1999, 1997; Kleiser et al., 2001; Mazzi et al., 2016; Sahraie et al., 2010, 1997; Weiskrantz et al., 1995). However, as with GY, these seem to reflect blindsight Type 2 rather than phenomenal awareness (Barbur et al., 1999; Sahraie et al., 2010; Sahraie et al., 1997).

As GY's subjective report demonstrates, patients often find it difficult to describe their blind field experience. One approach for obtaining a more objective measure has been to ask patients to match the perceptual characteristics of blind field stimuli with those experienced in the sighted field (Morland, 1999; Stoerig and Barth, 2001); a successful match would indicate that what is experienced in the blind field is indeed phenomenal. However, there are problems with this approach. Firstly, the use of a forced-choice paradigm might put pressure on the patient to find a match, even when none exists. The existing studies did not give patients to option to respond that no match could be made. Secondly, it is not clear what is being matched. For example, destriated monkey Helen appeared to match visual stimuli on the basis of their salience rather than physical appearance (Humphrey, 1974). Revealingly, she could not tell apart two stimuli which were physically very different but matched for discriminability against a third stimulus - suggesting it was unlikely that it was the visual experience of qualia what was being matched. The picture is further complicated by the fact that whether one observes blindsight type 1, blindsight type 2 and phenomenal vision appears to depend also on the measures used to assess these levels of awareness (Mazzi et al., 2016) and on the amount of repeated stimulation the patients are exposed to (Sahraie et al., 2013).

Perhaps the most convincing evidence of phenomenal awareness after a complete unilateral V1 lesion involves patient SL (Mazzi et al., 2016), a 48-year old woman suffering from hemianopia in her right visual field as a result of an ischemic stroke. SL's V1 lesion has been documented by both structural and functional MRI (Celeghin et al., 2015), with the latter showing no activity in her left V1 after full-field visual stimulation. SL has been extensively tested (Mazzi et al., 2016) for her ability to detect a range of stimulus features (such as orientation, colour contrast and apparent and real motion) in her blind field. The key manipulation in these studies was the use of both dichotomous and graded measures for assessing phenomenal awareness. The former involved a Yes-No judgment, as traditionally used in blindsight studies; the latter were obtained using the Perceptual Awareness Scale (PAS) which is composed of four levels visual experience $(0=$ No visual experience; 1 = Brief glimpse; 2 = Almost clear visual experience; 3 = Clear visual experience $($ Rams $\varnothing y$ and Overgaard, 2004). With the dichotomous awareness scale SL demonstrated Type 1 blindsight (above-chance accuracy without acknowledged awareness) for orientation, colour, contrast and real motion discrimination. The 
key finding was that, when using the PAS scale, SL reported some degree of awareness for all the stimulus features and her blindsight performance disappeared; in other words, stimulus detection was always accompanied by awareness. This appears to suggest that threshold to acknowledge conscious vision can change depending on the way awareness was assessed; a graded measure might be more sensitive to reveal awareness that is degraded yet nevertheless phenomenal. Furthermore, this is not an isolated finding, as there is also a prior report of a graded scale revealing phenomenal awareness in a blindsight participant (however in this case V1 lesion was not complete; Overgaard et al., 2008). Interestingly, a subsequent study (Mazzi et al, this issue) showed that SL's ability to consciously experience stimuli in her blind field was associated with the phenomenal awareness negativity (VAN; Koivisto and Revonsuo, 2003), a component thought to reflect phenomenal awareness, thought to originate in the temporal cortex (Tagliabue et al., 2016).

\section{Hemianopic completion}

A further line of evidence of phenomenal awareness in the absence of V1 comes from hemianopic completion. This phenomenon can occur when a visual stimulus is presented across the vertical meridian such that it intrudes both the blind and sighted hemifield; in such circumstance, some patients are able to perceive the complete figure. First described by Poppelreuter in 1917 who studied brain-damaged soldiers during the First World War (Poppelreuter, 1917), hemianopic completion has been replicated several times in patients both with or without blindsight (McCarthy et al., 2006; Sergent, 1988; Warrington, 1965, 1962) and the term "behindsight" (McCarthy et al., 2006) was proposed to describe this phenomenon. While some patients experience completion even when the blind field component is physically absent, it is most robust with complete stimuli which intrude both the intact and blind field (Marcel, 1998; Torjussen, 1976). This phenomenon has been shown not to be related to attentional deficits or incomplete damage to V1 enabling residual conscious vision in the hemianopic field (McCarthy et al., 2006). Symmetry, regularity and simplicity are amongst the features which most effectively produce hemianopic completion. Interestingly, the stimuli presented across the vertical meridian do not need to have veridical contours as hemianopic completion can also occur when the perceived object's form is generated by illusory contours, as in Kanizsa figures (Marcel, 1998). Specifically, when one of the inducing elements is presented to the blind field, patients report phenomenally experiencing the complete figure despite being unaware of the inducer in the blind field. The neural basis of hemianopic completing appears to involve anterior to retinotopic cortex in the lingual gyrus in the right occipital cortex, contralateral to the lesion; neither the ipsilesional nor the contralesional retinotopic areas V1-V3 seem to be involved (Weil et al., 2009),

\section{After-images}


A third line of evidence of phenomenal awareness in the blind field of patients with V1 lesions comes from the induction of after-images. In this phenomenon, first reported by Fuchs (Fuchs, 1921, 1920) hemianopic patients report perceiving a complete after-image (including its blind field component), despite consciously experiencing the inducing stimulus only in the sighted field. This effect has been replicated with various hemianopic patients (e.g. Bender and Kahn, 1949; Bender and Teuber, 1946; Marcel, 1998; Torjussen, 1976), with the blind field component appearing as vividly as its counterpart in the sighted field (Marcel, 1998). Blind field afterimages tend to be perceived only if the seen and unseen portions of the inducing stimulus are symmetrical across the hemifields and form a coherent pattern (Marcel, 1998).

There are also reports of after-images to stimuli presented exclusively in the blind field (Weiskrantz, 2002; Weiskrantz et al., 2002); the term "prime-sight" was coined to describe this phenomenon. Weiskrantz found that patient D.B., an extensively studied blindsight patient, could experience visible after-images for unseen stimuli of different colours, shapes, spatial frequencies and luminance changes. Furthermore, the after-images in the blind field were twice the duration of those induced in the sighted field and they conformed with the Emmert's law, i.e. changing in size as the viewing distance changes. Is this unequivocal evidence of phenomenal awareness without V1? Unfortunately, surgical removal of DB's right V1 cannot be confirmed by MRI due to intracranial wound clips. Thus whether DB has remaining striate cortex which could underlie these effects cannot be ruled out.

Since patient D.B. also shows signs of blindsight, one may be tempted to conclude that prime-sight and blindsight are related phenomena that co-occur. However, this seems not to be the case. Indeed, patient G.Y., another extensively studied patient with blindsight (type 1 or type 2 depending on the stimuli used), does not show prime-sight, i.e. after-image of an unseen stimulus presented only into the blind field. Nevertheless, G.Y. does experience afterimages in his blind field when the inducing stimulus intrudes both the blind and intact visual field. ${ }^{1}$

In summary, the phenomena of hemianopic completion and bilateral afterimages appear to be the most convincing examples of phenomenal awareness in the blind field. Importantly, both have been shown to occur in patients in whom the full extent of V1 lesions has been confirmed by structural imaging, and there exist little doubt as to whether the subjective report of the participant does indeed involve qualia. What is common to both

\footnotetext{
${ }^{1}$ It may appear as a contradiction to state that GY has Type 2 blindsight and also conscious vision. However, we would argue that blindsight is an operative definition which depends on behaviour. In other words, depending on the stimuli and task, the same patient can show either blindsight type 1, blindsight type 2 or residual conscious vision.
} 
of these is the stimulation of the intact visual field which enables blind field percepts to arise, and their neural basis appear to involve the intact hemisphere.

\section{Visual qualia induced by noninvasive brain stimulation}

A separate line of research has used Transcranial Magnetic Stimulation (TMS) to examine whether direct stimulation of intact cortical areas in patients with V1 lesions can induce conscious percepts. When TMS is applied over visually driven cortical areas, it can induce the perception of phosphenes (brief flashes of light). In patients with V1 lesions, phosphene induction provides a test for the ability of cortical regions to generate phenomenal awareness in the absence of V1. If TMS over intact extrastriate regions induces phosphenes even when V1 is fully lesioned, this would indicate that V1 is not necessary for phenomenal awareness. In contrast, if $\mathrm{V} 1$ is a prerequisite for the experience of visual qualia, then stimulation of ipsilesional extrastriate region would not induce phosphenes. The first attempt to induce phosphenes in blindsight patients involved GY, who had suffered a destruction of V1 in a car accident at the age of 8, with macular sparing (e.g. Cowey, 2004). When TMS was applied over GY's intact hemisphere, he perceived phosphenes similarly to control participants. Critically, stimulation of the damaged hemisphere failed to induce phosphenes (Cowey and Walsh, 2000). By contrast, application of TMS over the visual cortex of a retinally blind patient could reliably report phosphenes, demonstrating that blindness per se does not preclude phosphene perception. These findings thus supported the view integrity of $\mathrm{V} 1$ is necessary for phenomenal awareness arise, even when activity originates from extrastriate regions.

However, subsequent phosphene studies challenged this view by showing that, under certain circumstances, phosphenes can be perceived in the absence of V1. Even though GY failed to perceive phosphenes in his blind field when his damaged hemisphere was stimulated unilaterally, he did so when stimulation was applied bilaterally over the motion area V5/MT+ (Silvanto et al., 2007). Revealingly, when the intact hemisphere was stimulated at subthreshold TMS intensity, phosphenes could be reported only when the ipsilesional stimulation occurred earlier than the stimulation on the contralesional side rather than vice-versa. This result suggested an involvement of the intact hemisphere since the degree of activation of the intact hemisphere was found to determine the presence of blind field phosphenes. It may be that, in GY, blind field phosphenes were generated via the ipsilateral representation of the contralesional V5/MT+. GY was also found to phenomenally experience colours in his blind hemifield, when bilateral application of TMS was applied following chromatic adaptation (Silvanto, Cowey, \& Walsh, 2008; see Romei, Thut \& Silvanto, 2016, and Silvanto, Muggleton \& Walsh, 2008, for details on the TMS-adaptation paradigm). This effect was driven by adaptation of the intact visual field, as adaptation restricted to the blind field failed to modulate phosphene colour (see Fig. 1). The necessity for 
bilateral application of TMS mirrors the findings on hemianopic completion and afterimages in which involvement of the intact hemisphere appears to be crucial for blind field percepts to arise.
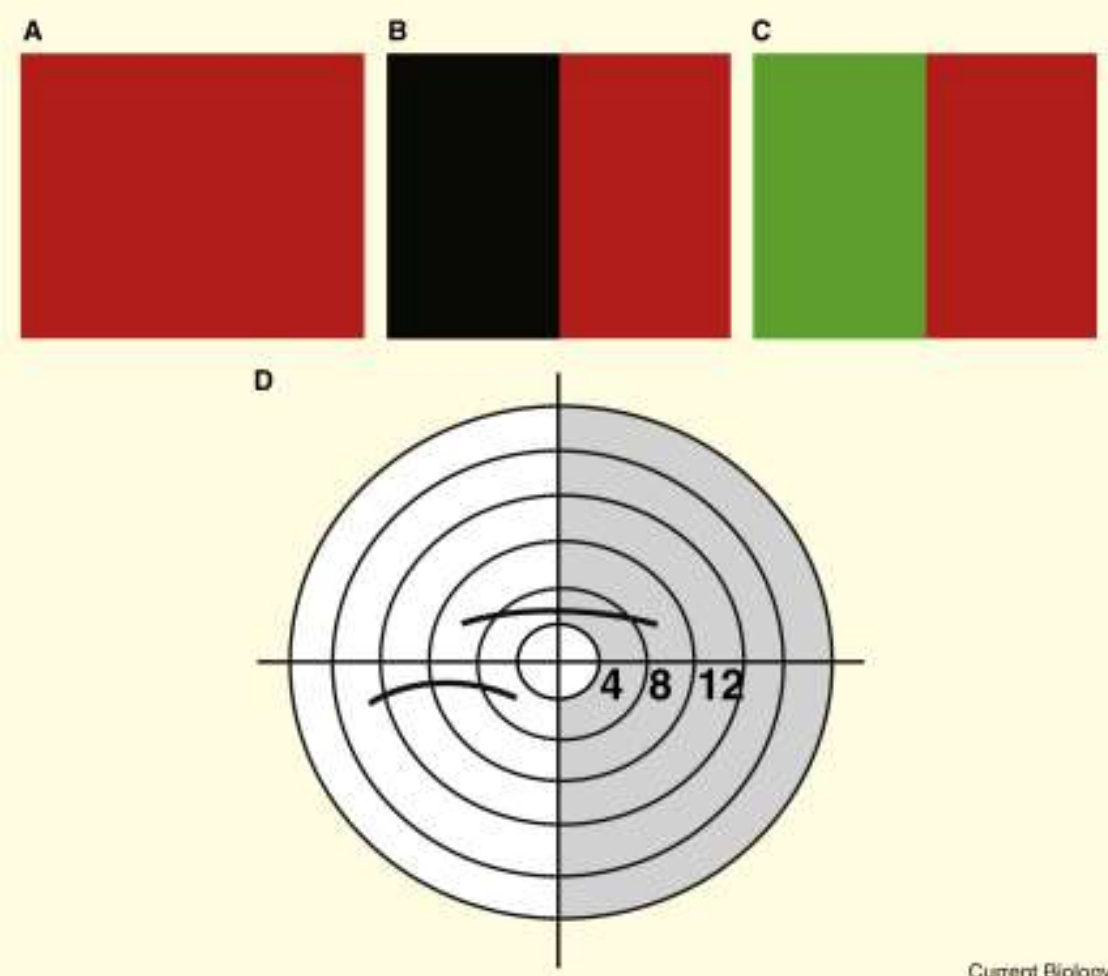

Curent Biology

Fig. 1. Adaptation stimuli presented before bilateral TMS administration on both GY's V5/MT+: (A) uniform red (or green) rectangle completely covering the monitor; $(B)$ coloured (red or green) rectangle restricted to a single hemifield (left or right) with the other half of the monitor filled in black; $(C)$ red and green rectangles respectively presented in the two hemifields. (D) Examples of phosphene location. The grey area indicates the GY's blind hemifield (from Silvanto et al., 2008. Reprinted with permission).

In the above TMS studies, unilateral application of TMS failed to induce phosphene, indicating that the damaged hemisphere on its own fails to generate conscious blind field percepts. Strikingly, there are recent reports of blind field phosphenes when TMS is indeed restricted to the damaged hemisphere. In a study by Mazzi and colleagues (Mazzi, Mancini, \& Savazzi, 2014), two patients with homonymous hemianopia, fully lacking in V1, reported phosphenes in their blind field when TMS was applied over the ipsilesional intraparietal sulcus (IPS). Data from both patients could be adequately fitted into psychophysical threshold functions (which did not differ from healthy controls) and their perceptual qualities were similar to those reported by controls. It is also worth noting that these patients were tested relatively soon after their lesion, thus these results are unlikely to reflect new abnormal connectivity as has been found to be the case in GY whose lesion occurred at the age of 8 (Bridge et al., 2008; Silvanto et al., 2009). This finding is of great theoretical interest, as it provides the first robust evidence that activation originating from extrastriate regions can reach awareness in the absence of V1. 
The spatio-temporal neural dynamics of blind field phosphenes have been examined with TMS-EEG in a patient with right homonymous hemianopia (SL) (Bagattini et al., 2015) and in a patient with superior altitudinal hemianopia (AM) (Mazzi, Mazzeo, \& Savazzi, 2017). The results revealed a critical time window at around 70$100 \mathrm{~ms}$ after the application of TMS over the intraparietal sulcus in which the amplitude of phosphene present trials differed significantly from the amplitude of phosphene absent trials. This effect was locally circumscribed to the site of stimulation (IPS), implicating the parietal lobe as an early and independent generator of conscious experience (see Fig. 2). As regards the altitudinal hemianopic patient only, phosphenes were also reliably detected while stimulating his occipital cortex. Importantly, the first time-window in which the presence of phosphene significantly modulated the EEG activity was the same for the two stimulation sites (occipital and parietal lobes), indicating that the emergence of phenomenal awareness may have no absolute need for recurrent processing between V1 and extrastriate areas, since feedback activity would have required additional time and, thus, the effect would have been found later when stimulating parietal site.

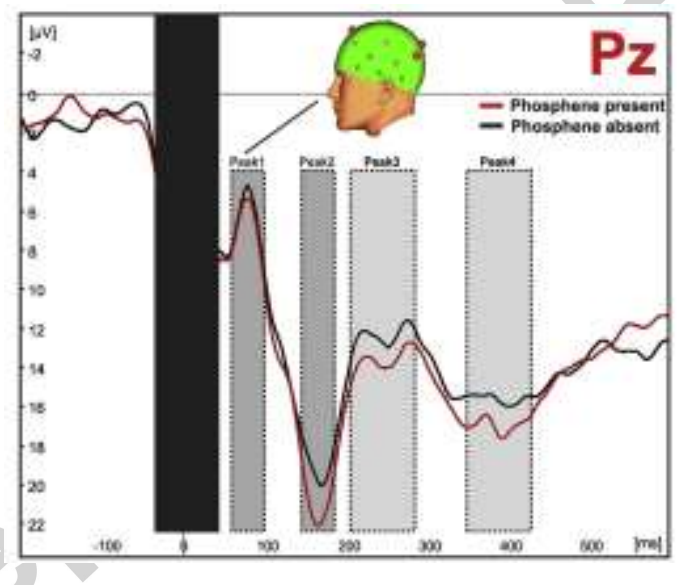

Fig.2. TMS-evoked potentials elicited stimulating the ipsilesional parietal cortex of a hemianopic patient whose $V 1$ was completely lesioned (from Bagattini et al., 2015. Reprinted with permission). Phosphene-present condition is represented in red, while phosphene-absent condition is represented in black. Dark grey dotted boxes highlight the time windows in which the two conditions are significantly different.

\section{Conclusions}

The study of phenomenal awareness in patients with V1 lesion has been the subject of much controversy. While numerous studies claim to have provided conclusive evidence for the presence of blind field qualia, a closer inspection often reveals difficulties in interpreting the results. So, where do we stand? On one hand, the fact that 
there are some demonstrations of awareness without V1 suggests that this region may not be the gatekeeper of awareness. On the other hand, one might wonder why there are only a handful of such demonstrations - if V1 is not necessary for experiencing visual qualia, why are cases of phenomenal awareness in its absence so few and far between, even though extrastriate regions continue to unconsciously process information. One possibility is that, while not being the gatekeeper of awareness, V1 is nevertheless important for creating conditions for awareness to arise (Silvanto, 2015). This may result from its central role in visual cortical hierarchy - V1 is the most important source of excitatory extrastriate input and engages in recurrent loops with a large number of visual areas; its lesions affect neural responsiveness throughout the visual cortex (e.g. Azzopardi et al., 2009; Rodman et al., 1989; Schmid et al., 2013, 2009). For example, one might speculate that inter-areal synchrony (which has been linked to awareness; see e.g. Murray et al., 2002; Wyart and Tallon-Baudry, 2008) cannot arise in the absence of V1, yet it can be artificially induced by techniques such as TMS which simultaneously depolarises a sizeable population of neurons and induces large-scale synchronous neural firing. Unconscious processes may not require neural synchrony and can thus occur in the absence of V1 (Silvanto, 2015). Thus a prudent conclusion is that, while V1 is not indispensable for awareness, it does seem to matter in most circumstances. 


\section{References}

Azzopardi, P., Cowey, A., 2001. Motion discrimination in cortically blind patients. Brain 124, 30-46.

Azzopardi, P., Cowey, A., 1997. Is blindsight like normal, near-threshold vision? Proc. Natl. Acad. Sci. U. S. A. 94, 14190-4.

Azzopardi, P., Fallah, M., Gross, C.G., Rodman, H.R., 2009. Response latencies of neurons in visual areas MT and MST of monkeys with striate cortex lesions. Neuropsychologia 41, 1738-1756. doi:10.1016/S00283932(03)00176-3

Bagattini, C., Mazzi, C., Savazzi, S., 2015. Waves of awareness for occipital and parietal phosphenes perception. Neuropsychologia 70, 114-125. doi:10.1016/j.neuropsychologia.2015.02.021

Barbur, J.L., Watson, J.D., Frackowiak, R.S., Zeki, S., 1993. Conscious visual perception without V1. Brain 116 ( Pt 6, 1293-1302. doi:10.1093/brain/116.6.1293

Barbur, J.L., Weiskrantz, L., Harlow, J. a, 1999. The unseen color aftereffect of an unseen stimulus: insight from blindsight into mechanisms of color afterimages. Proc. Natl. Acad. Sci. U. S. A. 96, 11637-41.

Bender, M.B., Kahn, R.L., 1949. After-imagery in defective fields of vision. J. Neurol. Neurosurg. Psychiatry 12, 196-204. doi:10.1136/JNNP.12.3.196

Bender, M.B., Teuber, H.L., 1946. Phenomena of Fluctuation, Extinction and Completion in Visual Perception. Arch. Neurol. Psychiatry 55, 627-658. doi:10.1001/archneurpsyc.1946.02300170075008

Benson, P.J., Guo, K., Blakemore, C., 1998. Direction discrimination of moving gratings and plaids and coherence in dot displays without primary visual cortex (V1). Eur. J. Neurosci. 10, 3767-3772. doi:10.1046/j.1460-9568.1998.00383.x

Bollini, A., Sanchez-Lopez, J., Savazzi, S., Marzi, C.A., 2017. Lights from the Dark: Neural Responses from a Blind Visual Hemifield. Front. Neurosci. 11, 290. doi:10.3389/fnins.2017.00290

Bridge, H., Thomas, O., Jbabdi, S., Cowey, A., 2008. Changes in connectivity after visual cortical brain damage underlie altered visual function. Brain 131, 1433-1444. doi:10.1093/brain/awn063Celeghin, A., Savazzi, S., Barabas, M., Bendini, M., Marzi, C.A., 2015. Blindsight is sensitive to stimulus numerosity and configuration: evidence from the redundant signal effect. Exp. Brain Res. 233. doi:10.1007/s00221-0154236-6

Cowey, A., 2010. The blindsight saga. Exp. Brain Res. 200, 3-24. doi:10.1007/s00221-009-1914-2

Cowey, A., 2004. The 30th Sir Frederick Bartlett lecture: Fact, artefact, and myth about blindsight. Q. J. Exp. Psychol. Sect. A 57, 577-609. doi:10.1080/02724980343000882

Cowey, A., Walsh, V., 2000. Magnetically induced phosphenes in sighted, blind and blindsighted observers. Neuroreport 11, 3269-73.

Ffytche, D.H., Guy, C.N., Zeki, S., 1996. Motion specific responses from a blind hemifield. Brain 119, 19711982. doi:10.1093/brain/119.6.1971

Ffytche, D.H., Zeki, S., 2011. The primary visual cortex, and feedback to it, are not necessary for conscious 
vision. Brain 134, 247-257. doi:10.1093/brain/awq305

Fuchs, W., 1921. Pseudo-fovea, in: A Source Book of Gestalt Psychology. Translated by Ellis WD. 1922/1938. London: Kegan Paul, pp. 357-65.

Fuchs, W., 1920. Completion phenomena in hemianopic vision, in: A Source Book of Gestalt Psychology. Translated by Ellis WD. 1921/1938. London: Kegan Paul, p. 344-56.

Holmes, G., 1945. Ferrier Lecture: the organization of the visual cortex in man. Proc. R. Soc. London. Ser. B, 361, 2239-59. doi:10.1098/rstb.2006.1832

Humphrey, N.K., 1974. Vision in a Monkey without Striate Cortex: A Case Study. Perception 3, 241-255. doi:10.1068/p030241

Kentridge, R.W., Heywood, C.A., Weiskrantz, L., 1999. Effects of temporal cueing on residual visual discrimination in blindsight. Neuropsychologia 37, 479-83.

Kentridge, R.W., Heywood, C. a., Weiskrantz, L., 1997. Residual Vision in Multiple Retinal Locations within a Scotoma: Implications for Blindsight. J. Cogn. Neurosci. doi:10.1162/jocn.1997.9.2.191

Kleiser, R., Wittsack, J., Niedeggen, M., Goebel, R., Stoerig, P., 2001. Is V1 Necessary for Conscious Vision in Areas of Relative Cortical Blindness? Neuroimage 13, 654-661. doi:10.1006/nimg.2000.0720

Koivisto, M., Revonsuo, A., 2003. An ERP study of change detection, change blindness, and visual awareness. Psychophysiology 40, 423-429. doi:10.1111/1469-8986.00044

Lamme, V.A.F., 2003. Recurrent Corticocortical Interactions in Neural Disease. Arch. Neurol. 60, 178. doi:10.1001/archneur.60.2.178

Marcel, A.J., 1998. Blindsight and shape perception: deficit of visual consciousness or of visual function? Brain 121 ( Pt 8, 1565-88.

Mazzi, C., Bagattini, C., Savazzi, S., 2016. Blind-sight vs. degraded-sight: Different measures tell a different story. Front. Psychol. 7. doi:10.3389/fpsyg.2016.00901

Mazzi, C., Mancini, F., Savazzi, S., 2014. Can IPS reach visual awareness without V1? Evidence from TMS in healthy subjects and hemianopic patients. Neuropsychologia 64, 134-144.

doi:10.1016/j.neuropsychologia.2014.09.026

Mazzi, C., Mazzeo, G., Savazzi, S., 2017. Markers of TMS-evoked visual conscious experience in a patient with altitudinal hemianopia. Conscious. Cogn. In press. doi:10.1016/j.concog.2017.01.022

McCarthy, R. a, James-Galton, M., Plant, G.T., 2006. Form completion across a hemianopic boundary: behindsight? Neuropsychologia 44, 1269-81. doi:10.1016/j.neuropsychologia.2006.01.036

Morland, A.B., 1999. Conscious and veridical motion perception in a human hemianope. J. Conscious. Stud. 6, 43-53.

Murray, M.M., Wylie, G.R., Higgins, B. a, Javitt, D.C., Schroeder, C.E., Foxe, J.J., 2002. The spatiotemporal dynamics of illusory contour processing: combined high-density electrical mapping, source analysis, and functional magnetic resonance imaging. J. Neurosci. 22, 5055-5073. doi:22/12/5055 [pii] 
Overgaard, M., Fehl, K., Mouridsen, K., Bergholt, B., Cleeremans, A., 2008. Seeing without Seeing? Degraded Conscious Vision in a Blindsight Patient. PLoS One 3, e3028. doi:10.1371/journal.pone.0003028

Pöppel, E., Held, R., Frost, D., 1973. Residual Visual Function after Brain Wounds involving the Central Visual Pathways in Man. Nature 243, 295-296. doi:10.1038/243295a0

Poppelreuter, W., 1917. Die psychischen Schädigungen durch Kopfschuss im Kriege 1914-1916 (die Storungen der niederen und hoheren Sehleistungen durch Verotsungen des Okzipitalhirns). Verlag von Leopold Voss, Liepzig.

Ramsøy, T.Z., Overgaard, M., 2004. Introspection and subliminal perception. Phenomenol. Cogn. Sci. 3, 1-23. doi:10.1023/B:PHEN.0000041900.30172.e8

Richards, W., 1973. Visual processing in scotomata. Exp. Brain Res. 17, 333-347. doi:10.1007/BF00234098

Riddoch, G., 1917. Dissociation of visual perceptions due to occipital injuries, with especial reference to appreciation of movement. Brain 40, 15-57. doi:10.1093/brain/40.1.15

Rodman, H.R., Gross, C.G., Albright, T.D., 1989. Afferent Basis of Visual Response Properties in Area MT of the Macaque. I. Effects of Striate Cortex Removal. J. Neurosci. 2033-2050.

Romei, V., Thut, G., Silvanto, J. 2016. Information-Based Approaches of Noninvasive Transcranial Brain Stimulation. Trends Neurosci 39, 782-795. doi: 10.1016/j.tins.2016.09.001

Sahraie, A., Hibbard, P.B., Trevethan, C.T., Ritchie, K.L., Weiskrantz, L., 2010. Consciousness of the first order in blindsight. Proc. Natl. Acad. Sci. U. S. A. 1-6. doi:10.1073/pnas.1015652107

Sahraie, A., Trevethan, C.T., Macleod, M.J., Weiskrantz, L., Hunt, A.R., 2013. The continuum of detection and awareness of visual stimuli within the blindfield: from blindsight to the sighted-sight. Invest. Ophthalmol. Vis. Sci. 54, 3579-3585. doi:10.1167/iovs.12-11231

Sahraie, A., Weiskrantz, L., Barbur, J.L., Simmons, A., Williams, S.C., Brammer, M.J., 1997. Pattern of neuronal activity associated with conscious and unconscious processing of visual signals. Proc. Natl. Acad. Sci. U. S. A. 94, 9406-11. doi:VL - 94

Schmid, M.C., Panagiotaropoulos, T., Augath, M.A., Logothetis, N.K., Smirnakis, S.M., 2009. Visually driven activation in macaque areas V2 and V3 without input from the primary visual cortex. PLoS One 4, e5527. doi:10.1371/journal.pone.0005527

Schmid, M.C., Schmiedt, J.T., Peters, A.J., Saunders, R.C., Maier, A., Leopold, D.A., 2013. Motion-Sensitive Responses in Visual Area V4 in the Absence of Primary Visual Cortex. J. Neurosci. 33, 18740-18745. doi:10.1523/JNEUROSCI.3923-13.2013

Sergent, J., 1988. An investigation into perceptual completion in blind areas of the visual field. Brain 111, 347373. doi:10.1093/brain/111.2.347

Silvanto, J., Cowey, A., Lavie, N., Walsh, V., 2007. Making the blindsighted see. Neuropsychologia 45, 334650. doi:10.1016/j.neuropsychologia.2007.06.008

Silvanto, J., Cowey, A., Walsh, V., 2008. Inducing conscious perception of colour in blindsight. Curr. Biol. 
doi:10.1016/j.cub.2008.08.016

Silvanto, J., Walsh, V., Cowey, A., 2009. Abnormal functional connectivity between ipsilesional V5/MT+ and contralesional striate cortex (V1) in blindsight. Exp. brain Res. 193, 645-50. doi:10.1007/s00221-009$1712-\mathrm{x}$

Silvanto, J. 2015. Why is "blindsight" blind? A new perspective on primary visual cortex, recurrent activity and visual awareness. Conscious Cogn. 32,15-32. doi: 10.1016/j.concog.2014.08.001.

Silvanto, J., Muggleton, N.G, Walsh, V. 2008. State-dependency in brain stimulation studies of perception and cognition. Trends Cog. Sci. 12(12):447-54. doi: 10.1016/j.tics.2008.09.004

Stoerig, P., Barth, E., 2001. Low-Level Phenomenal Vision Despite Unilateral Destruction of Primary Visual Cortex. Conscious. Cogn. 10, 574-587. doi:10.1006/ccog.2001.0526

Tagliabue, C.F., Mazzi, C., Bagattini, C., Savazzi, S., 2016. Early local activity in temporal areas reflects graded content of visual perception. Front. Psychol. 7. doi:10.3389/fpsyg.2016.00572

Teuber, H.L., Battersby, W.S., Bender, M.B., 1960. Visual field defects after penetrating missile wounds of the brain. Harvard University Press, Cambridge, MA.

Torjussen, T., 1976. Residual function in cortically blind hemifields. Scand. J. Psychol. 17, 320-322. doi:10.1111/j.1467-9450.1976.tb00247.x

Warrington, E.K., 1965. The effect of stimulus configuration on the incidence of the completion phenomenon. Br. J. Psychol. 56, 447-454. doi:10.1111/j.2044-8295.1965.tb00987.x

Warrington, E.K., 1962. The completion of visual forms across hemianopic field defects. J. Neurol. Neurosurg. Psychiatry 25, 208-17.

Weil, R.S., Plant, G.T., James-Galton, M., Rees, G., 2009. Neural correlates of hemianopic completion across the vertical meridian. Neuropsychologia 47, 457-464. doi:10.1016/j.neuropsychologia.2008.09.020

Weiskrantz, L. (1997). Consciousness Lost and Found: A Neuropsychological Exploration. Oxford: University Press.

Weiskrantz, L., 2002. Prime-sight and blindsight. Conscious. Cogn. 11, 568-581. doi:10.1016/S10538100(02)00015-6

Weiskrantz, L., 1998. Blindsight and commentaries, in: Hameroff, S.R., Kaszniak, A.W., Scott, A. (Eds.), Toward a Science of Consciousness II : The Second Tucson Discussions and Debates. MIT Press, pp. 371377.

Weiskrantz, L., Barbur, J.L., Sahraie, a, 1995. Parameters affecting conscious versus unconscious visual discrimination with damage to the visual cortex (V1). Proc. Natl. Acad. Sci. U. S. A. 92, 6122-6.

Weiskrantz, L., Cowey, A., Hodinott-Hill, I., 2002. Prime-sight in a blindsight subject. Nat. Neurosci. 5, 101102. doi:10.1038/nn793

Weiskrantz, L., Warrington, E.K., Sanders, M.D., Marshall, J., 1974. Visual capacity in the hemianopic fiels following a restricted occipital ablation. Brain 97, 709-728. doi:10.1093/brain/97.1.709 
Wyart, V., Tallon-Baudry, C., 2008. Neural Dissociation between Visual Awareness and Spatial Attention. J. Neurosci. doi:10.1523/JNEUROSCI.4748-07.2008

Zeki, S., Ffytche, D.H., 1998. The Riddoch syndrome: Insights into the neurobiology of conscious vision. Brain 121, 25-45. doi:10.1093/brain/121.1.25

\section{Highlights}

- We review evidence on whether phenomenal visual awareness is possible without V1

- Some evidence from hemianopic completion, afterimages and motion perception

- TMS can induce visual qualia in the blind field of hemianopic patients

- V1 appears not to be necessary for awareness in all circumstances 